\title{
O HIP HOP COMO APROPRIAÇÃO MULTICULTURAL: O CASO DAS RAPPERS E O PROJETO CEMINA
}

\section{THE HIP HOP HOW MULTICULTURAL APROPRIATION: THE CASE OF WOMEN RAPPERS AND THE CEMINA PROJECT}

William de Goes Ribeiro ${ }^{1}$

\section{Resumo}

O presente artigo discute sobre mulheres rappers no hip hop. O objetivo foi pensar como o multiculturalismo pode contribuir na construção da identidade de maneira positiva. $\mathrm{O}$ eixo da interrogação esteve no dualismo diferença-igualdade e na luta contra violência, preconceitos e estereótipos. A pesquisa indica potenciais para pensar a apropriação indébita da indústria cultural e para ver o hip hop como um espaço-tempo contextual. Concluo que é possível pensar um ângulo multicultural no hip hop. Nessa perspectiva, uma pista pode estar no papel das apropriações das mulheres rappers.

Palavras-chave: Multiculturalismo; hip hop; mulheres rappers; apropriação.

\begin{abstract}
The present article discusses about women rappers in hip hop. The aim was to think how the multiculturalism can contribute to the construction of identity in a positive manner. Its main axis of interrogation is the duality difference-equality and the fight against violence, prejudices and stereotypes. The research indicates potentials for think about the cultural industrial misappropriations and look at the hip hop how the contextual space-time. Thus, ended up that is possible think about one multicultural angle in the hip hop. In the perspective, one the scent can be in the role of women rappers appropriation.
\end{abstract}

Keywords: Multiculturalism; hip hop; women rappers; appropriation.

${ }^{1}$ Mestre em Educação, PPGE/ UFRJ. 


\section{DIVERS@!}

\section{Introdução}

Falar de hip hop não é uma tarefa simples visto que se trata de um conceito polissêmico (FOCHI, 2007; RIBEIRO, 2008). Há quem pense que se trata de um gênero musical. Para outros, é uma dança. Na opinião de outrem, pode ser um estilo de vida. Num determinado lugar, ele pode ser entendido como algo marginal, sem valor e/ ou até mesmo ultrapassado. No entanto, em alhures se desenvolvem práticas críticas e criativas, onde se questiona o poder desigual em nossa sociedade, produzindo cultura. Assim, orquestram-se discursos de variadas ordens que chegam ao imaginário social, uns com mais força e outros com menos, levando pessoas a perceberem, ou não, o seu potencial político (RIBEIRO, 2008, 2009; HERSCHMANN ; GALVÃO, 2008; MORENO ; ALMEIDA, 2008).

A partir dessas considerações iniciais, procuro desenvolver no presente texto a idéia do hip hop enquanto apropriação (ARCE, 1999), buscando romper com visões reducionistas e até mesmo preconceituosas do fenômeno. Num outro ângulo, procuro argumentar, ademais, que essas apropriações podem tomar itinerários políticos e enfrentamentos multiculturais. Em outras palavras, desenvolvo o argumento de que o hip hop também pode ser entendido enquanto uma prática social multicultural. Falar sobre experiências de rappers femininas, tal como aprofundo em discussão a seguir, significa adentrar, ainda que não somente, em questões de gênero, raça/ etnia, central para o quadro teórico a que me refiro.

Segundo Gonçalves ; Silva (2003, 2006), o multiculturalismo nasce nos movimentos sociais, resultado de um jogo das diferenças, que é mantido de acordo com seus múltiplos contextos sociais. Uma questão que destacam os referidos autores é que sua origem encontrase especificamente nos movimentos negros, sobretudo, estadunidenses, na medida em que esses sujeitos sociais sofrem o peso da discriminação, dos preconceitos e das injustiças sociais através da cor da pele e pelo entendimento essencializado de raça. A luta pelos direitos civis nos EUA marcou não só a história desse país, mas também a humanidade, como um ponto de eclosão da resistência à imposição cultural hegemônica.

Esses questionamentos passaram ao longo do tempo a incluir os movimentos feministas, homossexuais, indígenas, dentre outros, resultando numa outra lógica de apropriação do espaço público e discursivo que não condizem com os projetos neoliberais da exaltação do exótico (CANEN, 2007). Ou seja, não se trata de apenas exaltar "as diferenças" como valor agregado da humanidade, mas de questionar a construção de preconceitos, discriminação, estereótipo, desigualdade e demais injustiças sociais. 
A partir desse horizonte inicialmente destacado, num primeiro momento, penso em hip hop junto a autores que me ajudam a pensá-lo como apropriação. Nesse momento, teço especificidades acerca do referido movimento cultural no Brasil. Busco ressaltar, a seguir, algumas possíveis relações entre o hip hop e o multiculturalismo. Posteriormente, priorizo, no presente texto, um projeto intitulado como "Hip hop pela não violência contras as mulheres", desenvolvido pela ONG CEMINA (Comunicação, Educação e Informação em Gênero), que nos ajuda a trazer refletir algumas questões de interesse. Ao final, busco uma pausa à guisa de considerações.

\section{Algumas reflexões acerca do movimento hip hop no Brasil: discutindo as apropriações}

Nesse momento, cabe ilustrar questões concernentes às discussões que estão sendo mantidas em torno do hip hop. Seria esse movimento uma tribo urbana e/ ou um movimento social? Estaria ele restrito às questões de classe social e/ ou raça/ etnia? É possível encontrar questões de gênero? Conforme anteriormente mencionado, aprofundo um pouco mais essa problematização relacionando-a ao conceito de apropriação (ARCE, 1999).

Mafessoli (2006) nos oportuniza reverberações associadas ao quotidiano, ao sentimento, ao prazer de "estar junto à toa", ao "ombro a ombro", à relação com o próximo, se constituindo como "cimento", parafraseando o autor, de uma "massa" formada com/ pelas diferentes "tribos". Nessa visão de mundo, as pessoas ocupam diferentes papéis, "agrupadas", sem objetivo em comum específico; diferentemente da idéia do individualismo modernista e da lógica da razão "verdadeira". Para o referido autor, a humanidade se sustenta no sentimento de pertencimento, compartilhado e coletivo, razão pela qual as pessoas se reúnem e se aglomeram, formando o que metaforicamente o autor retoma, a idéia de tribo, um neotribalismo.

Em termos socioantropológicos, o olhar recai para o local, para as comunidades, para os grupos, para a vida em seu dia-a-dia. Vivemos, segundo o mencionado autor, em tempos marcados pelo efêmero, pelo dinamismo e pelo policulturalismo presente nos costumes, o habitus e o ethos. Essa ideia traz consigo o relativismo, em enfrentamento ao pensamento único, racional e linear. Indubitavelmente, contrário ao individualismo e a uma lógica que o próprio Mafessoli denomina de "dever-ser". Uma lógica que atribuiu à "massa”, desacreditada das grandes instituições e de representantes políticos, em desesperança nas transformações e 


\section{DIVERS@!}

ditames de alhures, voltando-se às comunidades e/ ou tribos de pertença, através do prazer de estar junto, da solidariedade e do sentir comum-unidades.

Essa posição anteriormente exposta vai de encontro a abordagens que discutem o político nas relações sociais. Fochi (2007), por exemplo, questiona se o hip hop é um "movimento social ou tribo urbana". Nesse sentido, argumenta o mencionado autor que sem as características de movimento o hip hop não sobreviveria, caindo no esquecimento como um produto da moda.

Estas são as características que diferenciam os movimentos sociais de uma tribo urbana - conforme veremos adiante -, ou seja, a contestação, a contradição à ordem vigente, mediante uma situação indesejável; a existência de um adversário e uma meta a ser cumprida, causando algum impacto na sociedade onde se estabelece (FOCHI, 2007: p.65).

Não obstante, Moreno ; Almeida (2009) salientam o investimento na militância política, contrariando concepções que tendem a ver essa motivação como algo natural. As referidas autoras argumentam que para que haja esse investimento coletivo, as individualidades devem ter determinadas experiências que favoreçam esse caminho. No caso específico dos jovens envolvidos com o hip-hop de Campinas, o primeiro a destacar é a aproximação com a música e, em especial, o circuito que chamam de "black". Ou seja, existe uma influência do samba, do rap e das músicas que falam de uma determinada posição-desujeito - "identidade negra".

Um outro ponto diz respeito à experiência do racismo e da privação. As autoras referidas mencionam que os jovens viviam situações de violência física e simbólica, sobretudo, quando entrava em cena a cor da pele: "o rap, assim, indica para esses jovens uma outra forma de entender o mundo que os cerca. Ao mesmo tempo, lhes dá instrumentos para operacionalizar essa mudança de olhar" (MORENO ; ALMEIDA, 2009, p. 136).

$\mathrm{O}$ terceiro aspecto se relaciona com o que as autoras citadas chamam de mobilidade social relativa, juntamente com a sua moral correspondente. Isso significa, segundo Moreno e Almeida, que, nessa dimensão, a família apresenta um papel preponderante na trajetória hip hopper. As subjetividades são influenciadas pela família a buscar uma ascensão social, aprendendo a não aceitar a situação de miserabilidade vivida, o que, de certa maneira, é socializado, ajudando a construir um sentimento de pertencimento coletivo, influenciado, 


\section{DIVERS@!}

como dito, pela música "negra" de protesto. Nesse contexto, destaca-se uma presença marcante de um desejo por uma vida digna.

Moreno ; Almeida (2008) ampliam a visão do movimento hip hop para além das indústrias culturais. Podemos contar hoje com espaços de engajamento político a partir desses/ as jovens e isso é de extrema importância para compreender como ocorre sua socialização, a forma como compartilham seus conhecimentos e as suas trocas de experiências. Ademais, cabe pensar como e por que seus conhecimentos se tornam significativos a ponto de resultar no investimento dessa identidade (rapper, dançarino, grafiteiro ou ambas), sabendo que, nesses casos, não implica numa relação direta com o mercado.

Arce (1999) traz uma relevante discussão que se soma às abordagens anteriormente destacadas. O referido texto traz considerações relevantes à questão da indústria cultural capitalista do pós-guerra que viu na problemática do cenário juvenil um meio de despertar para um potencial mercado. As indústrias fonográficas, cinematográficas e televisivas, principalmente, através de um grande poderio publicitário produziram filmes, personagens de novelas, propagandas, diversão, discos etc. que capturaram desejos e sonhos. Essas mensagens influenciaram o imaginário social ao passo que interferiam e estereotipavam muitos movimentos sociais alterando os seus discursos, por exemplo, o punk, o funk e o hip hop.

Quantas pessoas hoje sabem que o punk já teve adeptos ao ideário anarquista, de ideologia pacifista, ambientalista, anti-racista e autogestionária? Quantas pessoas discutem o funk como resistência ao poder dominante? Enfim, quantos conseguem ver o hip hop além das mulheres, carrões e cordões de ouro dos clipes e filmes e/ ou então algo diferente de meninos de boné, calça larga, tênis e que falam muitas "gírias"?

Essas questões são retomadas de minha dissertação de mestrado, que se relacionam ao universo plural multicultural híbrido e político do hip hop (RIBEIRO, 2008). Em concordância com os autores que discutem essas questões, conforme citações anteriores, há determinadas características que impulsionam a militância dentro desse universo. Assim, através da ideia de apropriação o hip hop não pode ser entendido como algo estanque, tampouco como um universo feito somente por homens e/ ou por negros, e sim por um conjunto plural de seres humanos que compartilham determinadas condições, dentre eles/ elas, jovens que se identificam com uma causa em torno dos movimentos negros, movidos/ das pelas injustiças historicamente presentes na sociedade brasileira. Desta forma, portanto, 


\section{DIVERS@!}

destaca-se que há prejuízos sociais que impulsionam o investimento em suas identidades coletivas (o movimento negro, por exemplo). Mas também existem possibilidades cabíveis de vozes e apropriações de mulheres, negras ou não-negras, homossexuais ou não, dentre outros sujeitos orientados por outros marcadores identitários, dentro desse universo de questionamento político.

Portanto, não esperando o cânone de uma definição, exponho o que nesse momento entendo como um conceito, possibilitando, não só a mim, mas a tantas mãos, uma (re) construção discursiva do fenômeno: Hip Hop pode ser entendido como um movimento sóciocultural-político, associado às identidades negro-juvenis, abrangente de uma série de manifestações artísticas em um sentido transformador e crítico. Transformador das difíceis realidades vividas em diferentes contextos, nas denúncias e nas soluções; e crítico das relações sociais, desafiando preconceitos e discriminações, e de apreensão de direitos coletivos. Entretanto e contraditoriamente, pode ser apropriado de diferentes maneiras, o que lhe confere diversos sentidos, desde o simples consumo a sua gênese contestatória; envolto e parte de, não obstante, à diversidade, ao hibridismo, às múltiplas identidades e a complexidade dos dias de hoje.

\section{Por que uma apropriação multicultural?}

Na presente seção, busco, conforme anteriormente mencionado, tecer o argumento de que o hip hop pode ser entendido como um discurso possível de realidades vividas a partir de experiências de injustiças sociais, caracterizando um caminho multiculturalmente percorrido. Ou seja, potencializa-se a construção de um sentimento de pertencimento que extrapola o próprio hip hop, associando-o a questão de raça/ etnia, gênero etc. Essa é uma questão que aproxima os campos do multiculturalismo e o hip hop, pois, para ambos, a identidade é uma categoria central (DAYRELL, 2002, 2003; HERSCHMANN ; GALVÃO, 2008; CANEN ; CANEN, 2005; CANEN, 2007).

É perceptível que este movimento cultural se emaranha por direcionamentos políticos diversos e demandas sociais cotidianas em meio à pluralidade cultural. Da mesma forma, o multiculturalismo discute posições que vão desde concepções folclóricas (liberais) a visões críticas e pós-coloniais. Num ponto de vista folclórico, por exemplo, as diferenças não são discutidas de maneira que problematize as relações assimétricas de poder (CANEN, 2007, 


\section{DIVERS@!}

2008). Outros autores preferem usar a terminologia liberal ou neoliberal para a abordagem anteriormente descrita (CANDAU, 2008; MOREIRA ; CÂMARA, 2008).

Ou seja, é possível, nessa visão, que as diversas culturas convivem entre si, mas sem que se questione a assimetria entre elas. Para que fique mais evidente, é o mesmo que salientar as diferentes roupas, ritos, festividades etc., geralmente a partir das datas comemorativas (dia da consciência negra, do índio e outros), enquanto que todo o resto do ano letivo, inclusive nos momentos em que a vida é levada a sério (universidade, escola, trabalho, dentre outros), essas questões ficam obscurecidas.

Já numa perspectiva crítica, implicaria há o desafio dos preconceitos, dos estereótipos, e das diversas formas de discriminação (CANEN, 2007, 2008; CANDAU, 2008a, 2008b). Questões como a problematização da construção da branquidade (APPLE, 2001), por exemplo, ocupam a cena política. Questiona-se o fato dessa identidade tomar para si o padrão de excelência e denunciar a condição discriminatória étnico/ racial com a qual milhares de brasileiros tem sofrido há anos. Estão na agenda multicultural crítica (MCLAREN, 1997) questões como o machismo, xenofobia, homofobia, dentre outros componentes da intolerância cultural, todas elas formas de se colocar um determinado grupo social, ou indivíduo, na condição de superioridade ou de privilegiado.

Já numa posição pós-colonial, revela-se a fluidez através da qual as identidades são construídas e reconstruídas continuamente, num processo que incorpora não mais o sujeito iluminista entendido como fixo e nuclear (HALL, 2006). De acordo com o referido autor, identidades emergem a todo o momento de maneira fragmentada e contextual. Para o discurso pós-colonial não há uma essência que garanta o lugar estanque do pertencimento. Essa dimensão humana é fluida, ambivalente e muitas vezes contraditória. Nessa perspectiva, se desafia a própria condição na qual surgem os preconceitos e os estereótipos que geram a discriminação e o discurso como constitutivo da realidade (CANEN, 2007, 2008).

Em suma, faz-se necessário explicitar o que entendemos como identidade: num nível singular, compreende a forma híbrida com a qual somos constituídos, por exemplo: homem, heterossexual, espírita etc. Numa esfera coletiva, entra em cena a prevalência de um marcador identitário como a raça/ etnia, sexualidade, religião, dentre outras. Nessa dimensão, Canen (2007) ressalta os riscos de um congelamento identitário que pode resultar num fechamento em si próprio, como algo ligado a uma essência. Candau (2008) chama essa perspectiva de diferencialista por tender a resultar numa universalização de um particularismo. 
Por isso, numa abordagem defendida por Canen (2007), a categoria hibridização é fundamental por dar ênfase ao caráter de construção das identidades e das diferenças, chamando a atenção para a diferença na diferença. Seria o mesmo que dizer que quando se prioriza um determinado marcador, o negro, por exemplo, ainda que necessário em alguns casos, é pertinente atentar para o fato de que há outras identidades e interesses silenciados, mesmo que momentâneos. Seguindo o exemplo, os interesses de uma mulher negra, pobre e homossexual muito provavelmente não serão contemplados dentro da categoria "negro". Voltando ao hip hop, tendo como foco a construção das identidades, isso significa dizer que o hip hopper não possui esse pertencimento como exclusivo em sua vida, é preciso atentar para a diversidade cultural, pois os rappers podem se identificar também como negros, ou não, como homens ou mulheres, ou não, heterossexual, ou não e assim por diante.

\section{“Hip Hop pela não violência contra as mulheres"}

$\mathrm{Na}$ atual seção, procuro desenvolver análises do material empírico apreendido no endereço eletrônico do CEMINA, através do referencial teórico já anteriormente delineado. Tendo em vista as categorias sugeridas (identidade, hibridismo, multiculturalismo e hip hop), teço considerações paradigmáticas que caminham na linha investigativa de Arce (1999) na medida em que revela o hip hop como um espaço-tempo discursivo sujeito a apropriações e influenciado pelos múltiplos contextos, contrariando a ideia de que este movimento cultural é entendido como dança, música, estilo de vida e/ ou restrito ao universo masculino em sua essência, tal como é percebido em alguns discursos no senso comum.

Em parceria com a SPM (Secretaria de políticas para as mulheres), a ONG CEMINA, desenvolve um de seus projetos, intitulado "Hip hop pela não violência contra as mulheres". Trata-se de ações, tais como "oficinas" de produção musical, show e exibição de documentário no intuito de interferir nas bases que sustentam atos de violência contra o gênero feminino. Ainda que haja outros projetos em andamento, elaborados pelo grupo, que são de interesse social, as referidas ações a favor das questões de gênero, são consideradas pela própria ONG como um dos mais importantes.

Atentamos ao objetivo do projeto: 
O projeto Minas da Rima - As Mulheres do Hip Hop unidas Pela Eliminação da Violência Contra as Mulheres é o primeiro de uma série de atividades que o Núcleo de Juventude do CEMINA realiza para alertar a sociedade, em especial os (as) jovens, sobre este tipo de violência. Seu objetivo é introduzir no universo da cultura Hip Hop a perspectiva de gênero, a reflexão e a compreensão dos fatores que levam à violência contra a mulher. $\mathrm{O}$ que se quer é aproveitar o potencial questionador do Hip Hop para colocar em pauta este tema (CEMINA, 2009).

Fica patente a compreensão de que se deseja apropriar-se do hip hop e de seu potencial questionador para introduzir na pauta a violência contra a mulher. Esse parece ser um problema enfrentado e percebido pelas jovens rappers em seu cotidiano. Para que esse escopo seja alcançado, o projeto contou com seminários, oficinas e palestras, integrando pesquisa acadêmica, sociedade, comunidade, juventude e o próprio movimento cultural. CEMINA Comunicação, Educação e Informação em Gênero, assim como dito no endereço eletrônico do projeto. Trata-se de uma organização que há 14 anos vem trabalhando questões relacionadas aos direitos das mulheres, sempre com o foco na comunicação, em especial o rádio e a Internet $^{2}$.

Uma de suas produções sintetiza as ideias construídas pela ONG, o CD “Hip Hop pela não violência contra a mulher". Especificamente discutindo os sentidos, as letras das músicas reforçam o interesse por um mundo menos injusto para as mulheres e uma relação social em que os direitos humanos se façam presente. Através das letras elas denunciam: o caráter frágil da justiça, uma sociedade desigual e machista, o problema da violência familiar contra a mulher, o descaso da sociedade, a naturalização com o que essas questões são tratadas, o sofrimento e os prejuízos causados, inclusive psicológicos, o impacto na auto-estima, os vários tipos de violências (como a relação sexual forçada e o assédio moral).

Essas denúncias vão ao encontro da perspectiva multicultural crítica, exposta anteriormente, pelo fato de desafiar as injustiças sociais acometidas a qualquer grupo social (CANEN, 2007, 2008; CANDAU, 2008, MOREIRA ; CÂMARA, 2008; RIBEIRO, 2008, 2009). Isso porque entendemos que os preconceitos devem ser discutidos e questionados através dos discursos que constituem a realidade. A diferença/ identidade nessa direção é entendida como construção social, contextual e relacional, de modo que não se naturalize e/ ou reforcem os discursos de legitimação. Cabe salientar que, contrariamente a visão de que o hip hop é um universo só para homens, o que seria um preconceito, o movimento permite uma

\footnotetext{
${ }^{2} \mathrm{Cf}$. www.overmundo.com.br/agenda/hip-hop-pela-nao-violencia-contra-as-mulheres-1.
} 


\section{DIVERS@!}

Ribeiro

apropriação que discute outras questões sem infringir seus aspectos predominantes (classe social/ raça/ etnia).

O hip hop não vive só de denúncias. O projeto Minas da Rima aponta caminhos que são pensados através dos seminários, das palestras, mas também das experiências vividas pelas rappers. A música Calada não vou mais ficar revela o principal alicerce. Defendem a denúncia dos agressores como o cerne dos problemas das mulheres que sofrem agressões. Outras letras caminham no mesmo sentido: de cabeça erguida e não de boca calada (...).

Um outro ponto são os direitos humanos e a luta pela mudança nas leis: direitos humanos/ para mim e pra vocêl direitos humanos para nos proteger/ direitos humanos é um direito de mulher/ leis mais severas para o agressor/ é o que a gente quer. As leis, da forma que estão e são compreendidas, facilitam, para as rappers, a naturalização da violência. Quase todas as letras criticam o fato do pagamento de cesta básica não ser suficiente para sanar o crime do agressor, além do fato de que muitas vezes este se torna vitimizado quando, por exemplo, nas músicas trazem a fala do delegado: mas o que você fez para ele te bater. Nesse sentido, a delegacia de mulheres é apontada como uma grande conquista.

Por um outro ângulo, a presença machista no rap é criticada, porém apontada como um problema social como um todo, na medida em que se discute as questões de inoperância sobre a violência, até mesmo no próprio hip hop. Esse parece ser um problema enfrentado pelas jovens rappers, pois elas não percebem uma mobilização dos seus colegas rappers (homens) em relação ao tema que defendem como urgente na sociedade em que vivem. Todavia, a própria configuração do referido projeto, ainda que minoritário, em termos quantitativos, aponta que há espaços para outras lutas na esfera política para além da raça/ etnia e/ ou classe social: “a questão específica da violência contra a mulher ainda é muito pouco discutida nesse universo do Hip Hop, seja pela cultura machista no qual esses/ as jovens são criados/ as, seja pela banalização com que a violência é tratada, seja pela falta de percepção de que este é um problema social, e não pessoal a ser resolvido entre quatro paredes" (CEMINA, 2009). Na letra Direito de Mulher essa crítica também aparece: o rap luta pelos pobres/ luta pelos pretos/ e cadê os meus direitos?/ a rima tem um poder, a força e a liberdade/ e cadê os meus direitos?/ mas onde está o rap?/ Não luta pelos meus direitos?

Porém, a própria letra anteriormente destacada mostra que o rap é feito de sentidos e que esse não é propriedade de um bloco único e homogêneo de sujeitos, tampouco faz parte de uma essência, mas sim uma apropriação política multicultural em que determinados marcadores identitários se sobressaem, no jogo das diferenças (GONÇALVES ; SILVA, 


\section{DIVERS@!}

2003, 2006). E se o rap hoje tem a minha voz/ e conta a minha realidadel é porque as minas que são da rimal tem o poder, a força e a liberdade.

\section{Uma pausa no meio do caminho...}

Procurei desenvolver no presente texto a idéia do hip hop como apropriação, buscando romper com visões reducionistas e até mesmo preconceituosas do fenômeno. Procurei argumentar, ademais, que essas apropriações podem tomar itinerários políticos e enfrentamentos multiculturais. Assim, desenvolvi o argumento de que o hip hop também pode ser entendido enquanto uma prática social multicultural.

Num primeiro momento, foi preciso expor a conceituação de que parti em relação a essa prática cultural. Sobre isso, é compreensível a co - existência de vários discursos que perpassam o imaginário social, revelando a ausência de consensos sobre o que seria hip hop. Assim, coexistem visões que o associam ao mais variados aspectos: à dança, à música, ao estilo de vida etc. No entanto, é possível encontrar jovens no Brasil que se apropriam deste enquanto movimento social em prol de lutas que, não raro, carregam a presença de determinados marcadores identitários.

Nesse aspecto, se reconhece que o hip hop foi construído inicialmente por jovens negros e latinos, ainda que estes devam ser vistos em sua pluralidade, tal como foi o objetivo ressaltar no presente estudo. Nesse sentido, a presença de rappers desafiando a violência contra a mulher, aponta um caminho específico trilhado por outros sujeitos, problematizando a ideia reducionista de que se trata de um universo feito somente por homens.

Procurei, nesse horizonte, destacar a ideia de apropriação multicultural, na medida em que essas questões (raça/ etnia, gênero, classe social etc.) estão no cerne de ambos os debates, hip hop e multiculturalismo, envolvendo a categoria identidade. O multiculturalismo, não entendido como um consenso, e sim como um conceito polissêmico, numa perspectiva mais crítica, possui a finalidade de desafiar estereótipos, preconceitos, discriminações e injustiças sociais, o que nos remete às lutas das rappers da ONG CEMINA.

Não foi o objetivo esgotar o assunto, mas propor outras discussões a respeito do espaço que mulheres rappers vêm tendo no hip hop: sobre o que discutem? Como se relacionam com outras questões sociais? Há semelhanças com outros projetos? Em outros lugares? Países? Por outro ângulo, há espaço para outras lutas? Cabe ressaltar, não é o intuito 


\section{DIVERS@!}

negar a presença dos movimentos negros dentro do hip hop, mas, ao contrário, é preciso postar nosso mirante num lugar em que seja possível vislumbrar outras lutas, assim como a capacidade humana de se constituir enquanto ser plural.

\section{Referências}

APPLE, M. Políticas de direita e branquidade: a presença ausente da raça nas reformas educacionais. Revista Brasileira de Educação, Campinas, n. 16, p. 61- 67, jan. / abr. 2001.

ARCE, J. M. V. Vida de barro duro: cultura popular juvenil e grafite. Rio de Janeiro: editora UFRJ, 1999.

ASSIS, M. D. P. de; CANEN, A. Identidade negra e espaço educacional: vozes, histórias e contribuições do multiculturalismo. Cadernos de Pesquisa, São Paulo, v. 34, n. 123, p. 709724, set. / dez. 2004.

CANDAU, V. M. Multiculturalismo e educação: desafios para a prática pedagógica. In: MOREIRA, A. F. e CANDAU, V. M. (org.). Multiculturalismo: Diferenças Culturais e Práticas Pedagógicas. Petrópolis, RJ: Vozes, 2008, p. 13- 37.

CANEN, A. O multiculturalismo e seus dilemas: implicações na educação. Comunicação e Política. v. 25, n. 2, p. 91- 107, 2007.

CANEN, A. A pesquisa multicultural como eixo na formação docente: potenciais para a discussão da diversidade e das diferenças. Ensaio: aval. Públi. Educ., Rio de janeiro, v. 16, n. 59, p. 297- 308, abr. / jun. 2008.

CANEN, A. G.; CANEN, A. Rompendo Fronteiras Curriculares: o multiculturalismo na educação e outros campos do saber. Currículo sem Fronteiras, v.5, n.2, p.40-49, jul./dez. 2005. Disponível em www.curriculosemfronteiras.org. Acessado em: 01 de julho de 2008. 


\section{DIVERS@!}

CEMINA. Hip hop pela não violência contra as mulheres. Disponível em $<$ http://www.hiphopsemviolencia.org.br/downloads.htm> Acessado em: 01 de julho de 2009.

DAYRELL, J. O rap e o funk na socialização da juventude. Educação e Pesquisa, São Paulo, v. 28, n.1, p. 117-136, jan./jun. 2002.

DAYRELL, J. O jovem como sujeito social. Rev. Bras. Educ., n.24, p.40-52. dez./ 2003.

FOCHI, M.A.B. A. Hip Hop brasileiro: Tribo urbana ou movimento social? FACOM, Rio de Janeiro, v.17, n.1, p.61-69, 2007.

GONÇALVES, L. A. O.; SILVA, P. B. G. Multiculturalismo e educação: do protesto de rua a propostas e políticas. Educação e Pesquisa, São Paulo, v. 29, n. 1, p. 109-123, jan. / jun. 2003.

GONÇALVES, L. A. O.; SILVA, P. B. G. O jogo das diferenças: o multiculturalismo e seus contextos. 4. ed. Belo Horizonte: Autêntica, 2006.

HALL, S. A identidade cultural na pós-modernidade. 11. ed. Rio de Janeiro: DP\&A editora, 2006, $102 \mathrm{p}$.

McLAREN, Peter. Multiculturalismo crítico. Trad. Bebel Orofino Shaefer. São Paulo: Cortez, 1997.

MAFFESOLI, M. O tempo das tribos: o declínio do individualismo nas sociedades de massa. 4. ed. Rio de Janeiro: Forense Universitária, 2006.

MOREIRA, A. F. B.; CÂMARA, M. J. Reflexões sobre currículo e identidade: implicações para a prática pedagógica. In: MOREIRA, A. F.; CANDAU, V. M. (org.). Multiculturalismo: Diferenças Culturais e Práticas Pedagógicas. Petrópolis, RJ: Vozes, 2008, p. 38- 66. 
MORENO, R. C.; ALMEIDA, A. M. F. O engajamento político dos jovens no movimento hip-hop. Revista Brasileira de Educação, Campinas, v. 14, n. 40, p. 130-142, jan. / abr. 2009.

RIBEIRO, W. de G. Nós estamos aqui: O Hip Hop e a construção de identidades em um espaço de produção de sentidos e leituras de mundo. Diss. (mestrado) - PPGE, UFRJ, 2008.

RIBEIRO, W. de G. O currículo em um outro lugar: multiculturalismo, conhecimento e poder. São Carlos, $9^{\circ}$ Encontro de Pesquisa em Educação da Região Sudeste, ANPEd, 2009.

SEMPRINI, A. Multiculturalismo. Bauru, São Paulo: EDUSC, 1999, 178 p. 